\title{
ORIGINAL RESEARCH \\ $>$ PREVALENCE OF WORK-RELATED MUSCULOSKELETAL DISORDERS AMONG DENTAL STUDENTS IN SOUTHERN KARNATAKA DISTRICT
}

\author{
${ }^{1}$ Nusaibath M Shaikhji \\ ${ }^{2}$ Abdul Rahim Shaik \\ ${ }^{3}$ Shaikhji Saad \\ ${ }^{4}$ Padmakumar Somasekaran Pillai
}

\section{ABSTRACT}

Background: Musculoskeletal disorders are common amongst dental personnel including dental students when they are still in educational programs due to their work in a static posture. The objective of the study is to identify work-related musculoskeletal disorders in terms of perception of pain and stiffness experienced by the dental students and interns and to find the association between pain, stiffness and selected socio demographic variables.

Methods: A total of 236 subjects were selected from Yenepoya Dental College, Manipal Institute of Dental Sciences and A B Shetty Memorial Institute of Dental Sciences, Mangalore. The subjects were selected by using convenience method and were given closed-ended questionnaire to find perception of pain and stiffness experienced.

Results: The study revealed that $51.3 \%$ of dental students sometimes had pain in lower back and $44.4 \%$ in neck. $20.3 \%$ of subjects complained of having sometimes stiffness in neck and $19.9 \%$ of them had in lower back. It was observed that number of workdays per week had significant association $(p=0.01)$ with increase in frequency of pain. Frequency of stiffness was significantly associated with height $(\mathrm{p}=$ $0.02)$ and weight $(p=0.02)$. There was also significant association between intensity of pain and average number of work days per week $(p=0.017)$ and average number of patients treated per day $(p=0.012)$.

Conclusion: The study revealed that WMSDs are prevalent in dental students and interns. A significant association was found between musculoskeletal symptoms and socio-demographic variables like gender, height, weight, number of workdays per week and number of patients treated per day.

Keywords: Musculoskeletal disorders, frequency of pain, frequency of stiffness, intensity of pain, dental students, interns.

Received $20^{\text {th }}$ May 2015, revised $26^{\text {th }}$ May 2015, accepted $30^{\text {th }}$ May 2015

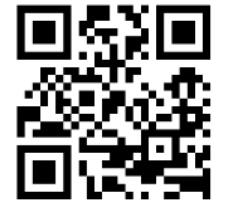

WwW.ijphy.org
DOI: $10.15621 /$ ijphy/2015/v2i3/67024

\section{CORRESPONDING AUTHOR}

\footnotetext{
${ }^{2}$ Associate Professor, Department of Physical therapy, Yenepoya Physiotherapy College, Yenepoya University, Mangalore.

${ }^{3}$ Resident PG, Department of Physical therapy, Yenepoya Physiotherapy College, Yenepoya University, Mangalore.

${ }^{4}$ Professor, Department of Physical therapy, Yenepoya Physiotherapy College, Yenepoya University, Mangalore.
}

\author{
${ }^{1}$ Nusaibath M Shaikhji \\ Resident PG, \\ Department of Physical therapy, \\ Yenepoya Physiotherapy College, \\ Yenepoya University, Mangalore.
}




\section{INTRODUCTION}

National Institute for Occupational Safety and Health (NIOSH) defines Musculoskeletal disorders (MSDs) as those injuries or disorders of the muscles, nerves, tendons, joints, cartilage, and supporting structures of the upper and lower limbs, neck, and lower back that are caused, precipitated or exacerbated by sudden exertion or prolonged exposure to physical factors such as repetition, force, vibration, or awkward posture. Work-related Musculoskeletal Disorders (WMSDs) include all musculoskeletal disorders that are induced or aggravated by work and the circumstances of its performance. ${ }^{1,2}$

WMSDs are common amongst dental personnel, who work in a restricted field that makes high demands on vision and requires them to sit in a static posture, use excessive force as well as undertake precise repetitive hand and wrist movements. ${ }^{3,4}$ The causes of WMSDs are multifactorial including not only workplace conditions and workplace exposures but also organizational, psychosocial and sociocultural variables, amongst others. ${ }^{5,6}$

Clinical dental procedures involve the application of precise motor skills and involve intense handeye coordination and concentration. Also mental stress during the long dental procedures, increased concentration of work, the length of the consultation and possible pre-existing pain conditions may also contribute to dental practitioners musculoskeletal pain. ${ }^{7}$ Dentists are among those who are more often susceptible to MSDs, their work includes risk factors that may lead to many pathologies such as tendinitis, synovitis, tenosynovitis and bursitis. ${ }^{8}$

It has been observed that even dental students experience MSDs when they are still in the educational programs. As the body positions used during work by dental students and dentists are similar, it is possible that dental students can experience musculoskeletal problems even during their clinical training period. An average of two out of three dental professionals experience occupational pain. MSDs account for the most common reason (29.3\%) for early retirement age in dentists worldwide. ${ }^{9}$

Despite the evidence of WMSDs in dentistry, research conducted among the students and interns in this region is very scanty. Hence the present study is aimed to describe the prevalence of WMSDs experienced by dental students and interns during their clinical work among selected dental colleges in and around Mangalore. The study also aimed to find the association between pain and stiffness experienced by dental students and interns and selected socio-demographic variables.

\section{MATERIALS AND METHODS}

A total of 236 subjects were selected from Yenepoya Dental College, Manipal Institute of Dental Sciences and A B Shetty Memorial Institute of Dental Sciences, Mangalore. Inclusion criteria were Final year dental students, Interns, Subjects having minimum of one year of clinical exposure. Exclusion criteria were any congenital deformity, Trauma to any parts of the body, musculoskeletal symptoms related to pregnancy and menstruation. Investigator approached each subject to explain the study and gained informed consent form. The details of clinical exposure and occurrence of WMSDs were assessed by using Musculoskeletal Disorder Rating Scale after obtaining the formal administrative approval from the concerned department during working hours. Validated questionnaire was obtained with permission from Shaik AR et al: Musculoskeletal disorders among dental surgeons. ${ }^{[10]}$

Musculoskeletal Disorder Rating Scale is divided into two parts such as, Socio Demographic Proforma: It consists of eight variables like Age, Gender, Field of dental practice, Working hours per day, Work days per week, Patients treated per day, Height and Weight of the subject. Subjects were asked to mark $(\sqrt{ })$ in the block along the category in which they belong. Pain and Stiffness Scale: It consists of three variables like Frequency of pain, Frequency of stiffness and Intensity of pain. Frequency of pain and frequency of stiffness further categorized into three sub headings like Always, Sometimes, Never. Subjects were asked to mark $(\sqrt{ })$ in the block along the category in which they belong. Regarding Intensity of pain, Numerical Pain Rating Scale (NPRS) was used. NPRS was rated as 0 (no pain), 13 (Mild pain), 4-6 (Moderate Pain) and 7-10 (Severe Pain). Subjects were asked to pick up a number according to their pain intensity. The questionnaire was filled up by subjects and was returned back to the investigator.

Ethical clearance to conduct the study was obtained from Yenepoya University Ethical Committee. After explaining the purpose of the study a written consent was obtained from the subjects on voluntary basis and the questionnaire was handed over to the dental students and interns to fill their responses.

Data were analysed using SPSS (Statistical Package for Social Sciences) version 17.0 software. The analysis was performed by using Fishers exact test 
and Chi-square $\left(\chi^{2}\right)$ test. $P$ value less than or equal to 0.05 was considered to be significant

\section{RESULTS}

Demographic data presented in Table 1 and 2 shows that majority (74.2\%) of the dental students and interns was females and $25.8 \%$ were male. $96.6 \%$ of these were in age group of $20-25$ years and $3.4 \%$ in the age group of 26-30 years. With regard to height and weight $69 \%$ of dental students were between151-165 and 24.6\% were $\geq 166$ centimeters of height. $40.7 \%$ of these were between 55-64 kilograms and $7.6 \%$ were $\geq 75$ kilograms of weight. With regard to the field of dental practice 19.4\% were posted in department of oral and maxillofacial surgery department. 2.6\% were posted in oral pathology department. Majority (64.0\%) of these were working 4-6 hours per day and $24.6 \%$ of these were working 1-3 hours per day. $92.4 \%$ of dental students were working for more than 5 days/week. Majority (74.1\%) of these was treating 1-3 patients per day and $5.6 \%$ of these were treating $\geq 11$ patients.

Table 1: Frequency and percentage distribution of dental students on personal characteristics

\begin{tabular}{|c|c|c|c|}
\hline Variables & Sample characteristics & Frequency & Percentage \\
\hline \multirow[t]{2}{*}{ Age(years) } & $20-25$ & 228 & 96.6 \\
\hline & $26-30$ & 08 & 3.4 \\
\hline \multirow[t]{2}{*}{ Gender } & Male & 61 & 25.8 \\
\hline & Female & 175 & 74.2 \\
\hline \multirow[t]{3}{*}{ Height $(\mathrm{cm})$} & $135-150$ & 15 & 6.4 \\
\hline & $151-165$ & 163 & 69.0 \\
\hline & $\geq 166$ & 58 & 24.6 \\
\hline \multirow[t]{4}{*}{ Weight (Kg) } & $45-54$ & 69 & 29.2 \\
\hline & $55-64$ & 96 & 40.7 \\
\hline & $65-74$ & 53 & 22.5 \\
\hline & $\geq 75$ & 18 & 7.6 \\
\hline
\end{tabular}

Table 2: Frequency and percentage distribution of dental students on Professional characteristics

\begin{tabular}{|c|c|c|c|}
\hline Variables & Sample characteristics & Frequency & Percentage \\
\hline \multirow[t]{9}{*}{ Field of dental practice } & $\begin{array}{l}\text { Oral Medicine and } \\
\text { Radiology }\end{array}$ & 23 & 9.8 \\
\hline & $\begin{array}{c}\text { Oral and Maxillo facial } \\
\text { surgery }\end{array}$ & 46 & 19.4 \\
\hline & Pedodontics & 17 & 7.2 \\
\hline & Orthodontics & 34 & 14.4 \\
\hline & Prosthodontics & 17 & 7.2 \\
\hline & Periodontics & 41 & 17.3 \\
\hline & Conservative dentistry & 28 & 11.9 \\
\hline & Community dentistry & 24 & 10.1 \\
\hline & Oral pathology & 06 & 2.6 \\
\hline \multirow[t]{3}{*}{$\begin{array}{l}\text { Average number of } \\
\text { working hour(s) per day }\end{array}$} & 1-3 hours & 58 & 24.6 \\
\hline & 4-6 hours & 151 & 64.0 \\
\hline & 7-9 hours & 27 & 11.4 \\
\hline \multirow[t]{2}{*}{$\begin{array}{c}\text { Average number of } \\
\text { workday(s) per week }\end{array}$} & $\leq 5$ & 18 & 7.6 \\
\hline & $>5$ & 218 & 92.4 \\
\hline \multirow[t]{3}{*}{$\begin{array}{l}\text { Average number of } \\
\text { patient(s) treated per day }\end{array}$} & $1-3$ & 175 & 74.1 \\
\hline & $6-10$ & 48 & 20.3 \\
\hline & $\geq 11$ & 13 & 5.6 \\
\hline
\end{tabular}

The data presented in Table 3 shows that in frequency of pain majority (51.3\%) of dental students sometimes had pain in the lower back and 9.3\% always had pain in lower back. $44.4 \%$ sometimes had pain in the neck and $33.1 \%$ sometimes had pain in the upper back $28 \%$ sometimes had pain in the right hand. 93.2\% never had pain their left elbow, $81.8 \%$ never had pain in left wrist.

Frequency of stiffness shows that $20.3 \%$ of dental students sometimes had stiffness in the neck, $14.0 \%$ sometimes had stiffness in the upper back. $17.3 \%$ of them sometimes had stiffness in the lower back. 2.6\% of them always had stiffness in lower back. With regard to the intensity of pain 3.0\% had 
severe pain in lower back followed by $0.8 \%$ in neck. $28.3 \%$ subjects had mild pain in the neck, $38.1 \%$ had mild pain in lower back and $23.3 \%$ had mild pain in upper back. Majority (93.6\%) of the dental students had no pain in left elbow.

Table 3: Description of Musculoskeletal disorders in terms of perception of pain and stiffness among dental surgeons

\begin{tabular}{|c|c|c|c|c|c|c|c|}
\hline \multirow{3}{*}{ Location } & \multicolumn{5}{|c|}{ Pain } & \multicolumn{2}{|c|}{ Stiffness } \\
\hline & \multicolumn{2}{|c|}{ Frequency } & \multicolumn{3}{|c|}{ Intensity } & \multicolumn{2}{|c|}{ Frequency } \\
\hline & $\begin{array}{c}\text { Always } \\
\text { n }(\%)\end{array}$ & $\begin{array}{c}\text { Sometimes } \\
\mathrm{n}(\%)\end{array}$ & $\begin{array}{l}\text { Mild } \\
\mathrm{n}(\%)\end{array}$ & $\begin{array}{c}\text { Moderate } \\
\mathrm{n}(\%)\end{array}$ & $\begin{array}{l}\text { Severe } \\
\mathrm{n}(\%)\end{array}$ & $\begin{array}{c}\text { Always } \\
\text { n (\%) }\end{array}$ & $\begin{array}{c}\text { Sometimes } \\
\mathrm{n}(\%)\end{array}$ \\
\hline Neck & $5(2.2)$ & $105(44.4)$ & $67(28.3)$ & $36(15.3)$ & $02(0.8)$ & $0(0)$ & $48(20.3)$ \\
\hline Upper back & $08(3.3)$ & $78(33.1)$ & $55(23.3)$ & $28(11.9)$ & $04(1.7)$ & $0(0)$ & $33(14.0)$ \\
\hline Lower back & $22(9.3)$ & $121(51.3)$ & $90(38.1)$ & $43(18.2)$ & $07(3.0)$ & $06(2.6)$ & $41(17.3)$ \\
\hline Right shoulder & $06(2.5)$ & $49(20.8)$ & $34(14.4)$ & $21(8.9)$ & $0(0)$ & $02(0.8)$ & $25(10.6)$ \\
\hline Left shoulder & $07(3.0)$ & $36(15.2)$ & $25(10.6)$ & $14(5.9)$ & $0(0)$ & $02(0.8)$ & $15(6.4)$ \\
\hline Right elbow & $03(1.3)$ & $25(10.6)$ & $20(8.5)$ & $08(3.4)$ & $0(0)$ & $0(0)$ & $10(4.2)$ \\
\hline Left elbow & $02(0.9)$ & $14(5.9)$ & $12(5.1)$ & $03(1.3)$ & $0(0)$ & $0(0)$ & $08(3.4)$ \\
\hline Right wrist & $04(1.7)$ & $45(19.1)$ & $46(19.5)$ & $07(3.0)$ & $0(0)$ & $0(0)$ & $20(8.5)$ \\
\hline Left wrist & $03(1.3)$ & $40(16.9)$ & $34(14.4)$ & $10(4.2)$ & $0(0)$ & $3(1.3)$ & $18(7.6)$ \\
\hline Right hand & $05(2.1)$ & $66(28)$ & $53(22.4)$ & $15(6.4)$ & $0(0)$ & $3(1.3)$ & $16(6.8)$ \\
\hline Left hand & $04(1.7)$ & $36(15.2)$ & $34(14.4)$ & $04(1.7)$ & $0(0)$ & $3(1.3)$ & $10(4.2)$ \\
\hline Right hip/thigh & $02(1.7)$ & $24(10.2)$ & $22(9.3)$ & $05(2.1)$ & $0(0)$ & $0(0)$ & $13(5.6)$ \\
\hline Left hip/thigh & $02(0.8)$ & $19(8.1)$ & $19(7.6)$ & $03(1.3)$ & $0(0)$ & $0(0)$ & $14(5.9)$ \\
\hline Right knee & $03(1.3)$ & $22(9.3)$ & $21(8.9)$ & $04(1.7)$ & $0(0)$ & $0(0)$ & $11(4.6)$ \\
\hline Left knee & $06(2.6)$ & $12(5.1)$ & $16(6.8)$ & $06(2.5)$ & $0(0)$ & $0(0)$ & $8(3.4)$ \\
\hline Right ankle & $05(2.1)$ & $26(11.0)$ & $19(8.1)$ & $10(4.2)$ & $0(0)$ & $0(0)$ & $7(3.0)$ \\
\hline Left ankle & $04(1.7)$ & $24(10.2)$ & $16(6.8)$ & $10(4.2)$ & $0(0)$ & $0(0)$ & $10(4.2)$ \\
\hline
\end{tabular}

Association between socio-demographic variables and musculoskeletal symptoms are presented in Table 4 which indicate that there was significant association was found between Frequency of pain and age (0.007) and there was significant association between frequency of pain $(p=0.001)$, stiffness $(p=0.0006)$ and gender. Significant association between number of work days per week and frequency of pain $(p=0.01)$. Statistically significant association was found between frequency of stiffness and height $(p=0.02)$. Weight also had significant association $(p=0.02)$ with frequency of stiffness. There was also significant association between intensity of pain and average number of work days per week $(p=0.017)$ and average number of patients treated per day $(p=$ 0.012 ).

Table 4: Association between frequency of pain, frequency of stiffness, intensity of pain, and the selected socio-demographic variables.

\begin{tabular}{|c|c|c|c|c|c|c|}
\hline \multirow{2}{*}{ Variables } & \multicolumn{2}{|c|}{ Frequency of pain } & \multicolumn{2}{|c|}{$\begin{array}{l}\text { Frequency of } \\
\text { stiffness }\end{array}$} & \multicolumn{2}{|c|}{ Intensity of pain } \\
\hline & $\begin{array}{l}\text { Chi } \\
\text { square }\end{array}$ & P value & $\begin{array}{l}\text { Chi } \\
\text { square }\end{array}$ & P value & $\begin{array}{l}\text { Chi } \\
\text { square }\end{array}$ & $P$ value \\
\hline Age & $0.007^{*}$ & 0.92 & 2.939 & 0.08 & 0.34 & 0.84 \\
\hline Gender & $0.001^{*}$ & 0.971 & 11.7 & $0.0006^{*}$ & 0.97 & 0.61 \\
\hline Field of practice & 4.05 & 0.852 & 5.65 & 0.68 & 10.66 & 0.82 \\
\hline $\begin{array}{l}\text { Average no. of } \\
\text { working hrs/day }\end{array}$ & 2.601 & 0.272 & 0.44 & 0.8 & 6.60 & 0.15 \\
\hline $\begin{array}{l}\text { Average no. of } \\
\text { work days/week }\end{array}$ & 6.5 & $0.01 *$ & 0.99 & 0.31 & 8.13 & $0.017^{*}$ \\
\hline $\begin{array}{l}\text { Average no. of } \\
\text { patients } \\
\text { treated/day }\end{array}$ & 4.7 & 0.09 & 5.19 & 0.07 & 12.85 & $0.012^{*}$ \\
\hline Height & 2.9 & 0.234 & 7.27 & $0.02 *$ & 5.50 & 0.23 \\
\hline Weight & 3.01 & 0.389 & 9.17 & $0.02 *$ & 9.995 & 0.12 \\
\hline
\end{tabular}




\section{DISCUSSION}

Dental students experience MSDs when they are still in the educational programs. As the body positions used during work by dental students and dentists are similar, it is possible that dental students can experience musculoskeletal problems even during their clinical training period.

The study was conducted to find the prevalence of WMSDs among dental students and interns in selected dental colleges in Mangalore. The study found that $86.4 \%$ of the students experienced WMSDs. $84.4 \%$ complained of having pain and 39\% subjects reported presence of stiffness.

A study conducted in Brazil found that 58\% of dentists reported complaints of musculoskeletal pain in one or more body regions. ${ }^{11}$ Low Back Pain (LBP) was the most common MSDs experienced followed by neck pain and then Upper Back Pain (UBP). ${ }^{12}$ The current study reveals that majority of subjects had complaint of low back pain and neck pain. 59.2\% had lower back pain, among these $38.1 \%$ had mild pain, $18.2 \%$ moderate and $2.9 \%$ severe. $44.4 \%$ complained of having neck pain among which $28.3 \%$ had mild pain, $15.3 \%$ had moderate pain and $0.8 \%$ had severe pain. The current study also found out that $20.3 \%$ of subjects complained of having stiffness sometimes in neck and $19.9 \%$ of them had stiffness sometimes in lower back.

A similar study conducted in Australia on prevalence and correlates of MSDs among a selection of undergraduate dental hygiene students showed that MSDs were most commonly reported by students at the neck (64.29\%), lower back (57.94\%) and shoulder (48.41\%) regions. ${ }^{12}$ The current study revealed that pain reported by dental students and interns was $44.4 \%$ and $59.3 \%$ in neck and lower back respectively.

The findings of current study revealed that frequency of pain was significantly associated with number of working days per week $(p=0.01)$. Significant association was also found between frequency of pain (0.001), frequency of stiffness $(p=0.0006)$ and gender. Statistically highly significant association was found between frequency of stiffness and height $(p=0.02)$ and Weight $(p=0.02)$.

A study was conducted in Malaysia indicated that the number of clinical working hours per week were statistically significant risk factors and also found that students who work for longer hours in clinic were 12 times more likely to report discomfort in one or more body region. Students with increased number of working hours per week were much more likely to report discomfort. ${ }^{13}$ Contrary to this the current study found that there was no significant association between average number of working hours per day and MSDs experienced by students and interns.

A similar study reported that age, gender and perceived general health status are strongly associated with chronic complaints and seeking medical care. ${ }^{14}$ A study conducted in India showed that the gender, height and weight of the dentists had no significant association with the frequency and intensity of pain and frequency of stiffness. The study also showed that there was no significant association between musculoskeletal symptoms experienced by dental surgeons and average number of working days per week. Contrary to this the current study revealed that there was significant association between musculoskeletal symptoms experienced by dental students, interns and average number of working days per week.

A study was conducted in Turkey to find prevalence of MSDs among Turkish dental students, which revealed that $86.0 \%$ of the students reported one or more musculoskeletal symptoms (ache, discomfort) in the neck, back, head and shoulder region. ${ }^{15}$ Another study conducted in Pakistan indicated that complaints of back pain were strongly related to the number of patients treated daily. ${ }^{16}$ The current study found that there was no significant association between pain and number of patients treated daily.

\section{CONCLUSION}

The study revealed that WMSDs are prevalent in dental students and in interns and various sociodemographic variables contributed to the musculoskeletal disorders experienced by the dental students. The association between the number of workdays per week by the dental students and pain experienced by them was statistically significant. A statistically significant association was also found between gender, height, weight and frequency of stiffness. Number of work days per week and number of patients treated per day was also significantly associated with intensity of pain.

\section{ACKNOWLEDGEMENT}

Authors acknowledge the great help received from the scholars whose articles cited and included in references of this manuscript. The authors are also thankful to all the subjects who participated in the study.

\section{REFERENCES}

1. Barr AE, Barbe MF, Clark BD. Work-Related Musculoskeletal Disorders of the Hand and 
Wrist: Epidemiology, Pathophysiology and Sensorimotor Changes. Josrthop sports physther. 2004; 34(10):610-627.

2. Pradeep JR. Back pain amongst dentistry students at the University of Western Cape. University of the Western Cape.2008; 1-3.

3. Graham C. Ergonomics in Dentistry, Part 1.Dent Today.2002; 21(4):98-103.

4. Lindfors P, Von Thiele U, Lundberg U. Work characteristics and upper extremity disorders in female dental health workers. J Occup Health. 2006; 48:192-197.

5. Waddell G, Burton A.K. Occupational health guidelines for the management of low back pain at work: evidence review. Occup Med. 2001; 51(2):124-135.

6. Khan S A, Chew K Y. Effect of Working Characteristics and taught Ergonomics on the Prevalance of Musculoskeletal Disorders Amongst Dental Students. 2013;14(1)1.

7. Al Wazzan KA, Almas K, Al Shethri SE, ALQahtani MQ. Back \& neck problems among dentists and dental auxiliaries. J Contemp Dent Pract. 2001; 2(3):17-30.

8. Doorn JWC. Low back disability among selfemployed dentists, veterinarians, physicians and physical therapists in The Netherlands. ActaOrthopScand Suppl. 1995; 263:1-64.

9. Madaan V, Chaudhri A. Prevalence and risk factors associated with musculoskeletal pain among dental students of MGM Dental College: a cross-sectional survey. Journal of contemporary dentists. 2012; 2(2): 22-27.

10. Shaik AR, Sripathi Rao BH, Husain A, D'Sa JL. Association between Musculoskeletal
Symptoms Experienced By Dentists and Selected Socio Demographic Variables in a Southern Karnataka District. Kathmandu Univ. Med J. 2012; 38(2):9-13.

11. Santos Filho SB, Barreto SM. Occupational activity and prevalence of upper-limb and back pain among dentists in Belo Horizonte, Minas Gerais State, Brazil: a contribution to the debate on work-related musculoskeletal disorders. Cad Saúde Pública 2001; 17(1):18-193.

12. Hayes MJ, Smith DR, Cockrell D. Prevalence and correlates of musculoskeletal disorders among Australian dental hygiene students. Int J Dent Hygiene. 2009; (7):176-181.

13. Hoe VC, Urquhart DM, Kelsall HL, Sim MR. Ergonomic design and training for preventing work-related musculoskeletal disorders of the upper limb and neck in adults. Cochrane Database Syst Rev. 2012 Aug 15;8.

14. Yamalik N. Musculoskeletal disorders (MSDs) and dental practice Part 2. Risk factors for dentistry, magnitude of the problem, prevention, and dental ergonomics. Int Dent J. 2007; 57:45-54.

15. Tezel A, Kavrut F, Tezel A, Cara C, Demit T, Kavrut R. Musculoskeletal disorders in left and right-handed Turkish dental students. int J neurosci. 2005; 115(2):255-66.

16. Afridi S, Jamil B, Gilani SI. Frequency of musculoskeletal pain in dentists working in public and private sector dental hospitals of Peshawar, Pakistan. J Pak Dent Assoc. 2012; 21(4):197-201.

\section{Citation}

Shaikhji, N., Shaik, A., Saad, S., \& Somasekaran Pillai, P. (2015). PREVALENCE OF WORK-RELATED MUSCULOSKELETAL DISORDERS AMONG DENTAL STUDENTS IN SOUTHERN KARNATAKA DISTRICT. International Journal of Physiotherapy, 2(3), 518-523. 